A Commentary on 'A Role for the Compulsory Study of Literature in Accounting Education'

Lisa Evans and Ian Fraser

University of Stirling

Address for Correspondence:

Lisa Evans, Division of Accounting and Finance, Stirling Management School, University of Stirling, Stirling FK9 4LA, Tel.: +44 (0)1786 467283, email: lisa.evans@stir.ac.uk 


\section{A Commentary on 'A Role for the Compulsory Study of Literature in Accounting Education'}

We share [author]'s enthusiasm for literature. Original and fresh thinking is to be welcomed. We are less convinced by some of [author's] specific arguments for incorporating literature in accounting education.

[author] suggests that interdisciplinary links in education can foster marketable skills in graduates. Teaching literature, s/he argues, addresses the limitations of a technical, skills-based and vocational accounting education which, inter alia, seeks to reduce ambiguity. Literature, on the other hand, exposes students to ambiguity, and engaging with ambiguity encourages innovative, creative and original thinking.

We believe that the suggestion that accounting aims to reduce ambiguity is simplistic. Ambiguity is intrinsic to (even) mainstream accounting. Accruals, provisions, asset lives and realisable values, as well as concepts such as materiality, fair value, fair presentation and substance over form are all ambiguous and require judgement. Students learn that different accounting policies and assumptions lead to dramatically different results. Contemporary accounting standards (arguably) involve a principles-based approach, not one based on unambiguous rules. Students engaging fully with these issues will not see accounting as a merely technical skill, but will recognise and be equipped to deal with its complexities.

Additionally, students are introduced increasingly to critical and interdisciplinary accounting research, which achieves many of the objectives desired by [author], widening students' horizons and broadening their education. This goes further than [author's] suggestions, exposing students not only to literature, but also to 
other disciplines - including sociology, economic and social history, politics and law pertinent to a rounded education. It even experiments with 'new aesthetic forms' (p.9); as for example in the poetry published in Critical Perspectives on Accounting or the 'Literature and Insights' in Accounting, Auditing and Accountability Journal. Thus, far from being merely technical skills-based education, accounting curricula already draw on different 'knowledges' and encourage reflective thinking and interactive learning. This may indeed go some way towards equipping graduates with the knowledge and skills required to bridge 'cultural divisions' (p. 12). However, we are sceptical as to the extent that this, or a literature education, could be 'a way out of increasing cultural disadvantage' (p. 13). Indeed, it might be argued that to compete with graduates from the 'elite' institutions, and the social background these may imply, requires superior technical accounting skills.

[author] further argues that exposing students to world literature will help to prepare them for the cultural complexity of international business: 'A country's or region's literature gives insight into character, thought-patterns, decision processes, zeitgeist and the very fabric of expression' (p.9). We agree that understanding other cultures is essential for international cooperation, and that literature may play a valuable role. However, some of the benefits claimed by [author] may well be lost in translation. Instead, greater emphasis on foreign language education is likely to create a better basis for appreciating cultural complexity than, to use [author]'s example, the reading of War and Peace.

[author] next takes issue with a recent paper by Badaracco (2006), which promotes the use of literature in management education. [author]'s view is that Badaracco's approach misses an opportunity to 'impart each work as an aesthetic whole' and as an educational opportunity to convey also other skills, such as good 
writing. Examples of simple and clear style in world literature are presented, but here [author] acknowledges the difficulties of translation: 'whoever translates betrays' (p.19). It seems, then, that inevitably much of the discipline and beauty of good writing may be as lost in translation as the cultural subtleties referred to above.

It is surprising that Badaracco is singled out for criticism, but that no reference is made to earlier papers on the use of literature in management or accounting education (Czarniawska-Joerges and Guillet de Monthoux, 1994; Czarniawska and Rhodes, 2006; Stone, 2001; Phillips, 1995). Perhaps [author] might also accuse this work of encouraging fragmentation. But we are surprised that it is not acknowledged. [author] does not explain whether s/he advocates the incorporation of standalone literature modules in an accounting programme, or rather the inclusion of literature elements within existing accounting modules. Both raise practical considerations. Given the increasing complexity of our subject, the demands of professional accreditation, and the desire to incorporate interdisciplinary and critical elements, we cannot, simply write off curriculum and time constraints as 'dangerous and defeatist' (p. 20).

How could a literature module in an accounting degree, or a literature component in an accounting module, be delivered, and more importantly, assessed? If it was to be delivered by accounting academics, would we be likely to identify suitable individuals? Most importantly, how could we convince our stakeholders (students, professional bodies, employers) that such innovations are worthwhile or more so than the incorporation of disciplines (e.g. law, economics, foreign languages) clearly pertinent to accounting education.

Our reservations are reinforced by some major issues that remain unaddressed. If there is a clear logic for importing literature into accounting degrees then it appears 
that similar arguments are applicable to other academic disciplines; for example, engineering, law and medicine. Indeed, given the attempts - with varying amounts of success - to incorporate reflective and critical elements in accounting education, as well as the judgment and subjectivity that is in any event intrinsic to accounting measurement, it may be that education for some other professions, may be more embedded in a functionalist paradigm (see e.g. Riahi-Belkaoui, 1996) than is accounting, and perhaps therefore, more in need of the creative and 'mould-breaking' elements which a focus on literature might bring. This is not to deny that accounting education would benefit from such innovation; merely that the paper doesn't argue convincingly for the incorporation of a literature element specifically in accounting education rather than in (technical and vocational) education generally.

Perhaps there is potentially a wider argument here for the incorporation of a (perhaps preliminary?) liberal arts element in the university education of those whose intention is to train for the professions. This is not such a radical idea as it may appear to some; in the past Scottish tradition, divinity or law degrees were typically preceded by a general arts degree incorporating such courses as moral philosophy or logic and the study of a foreign language. Indeed foreign language study may have particular advantages in realizing the author's objective to enhance the cultural awareness, and ultimately the marketability, of accounting graduates. Of course, implementing such a model would have financial implications - and certainly so at a time of global financial crisis. The necessary time may not appeal to our frenetic world. A pre-university baccalaureate along continental European lines may be a (possibly) more attractive alternative.

It is unclear whether the author is arguing for a focus within accounting degrees on literature per se or on literature dealing specifically with accounting or 
accounting related themes. It appears that the former is the case although the paper does not make this explicit. The author does not indicate that $\mathrm{s} /$ he regards the latter as a viable alternative despite the fact that there is a surprisingly rich variety of such literature. While many authors (including Shakespeare, Dickens and Trollope) make references of varying extent to accounting, there is a limited but varied literature that focuses on accounting, and accounting-related themes, in much greater depth. This ranges over a variety of cultures, historical eras and geographies. Examples from English literature include Chaucer's Canterbury Tales (see Parker, 1999, Buckmaster and Buckmaster, 1999), Dickens' Hard Times (see Fraser et al, 2006), Somerset Maughan's autobiographical Of Human Bondage (see Boys, 1994) and Bruce Marshall's The Accounting (also published under the title The Bank Audit, see West, 2001). Maltby (1997), Jackson (1992), or Evans (forthcoming) provide relevant examples relating to continental European literature.

It is not difficult to envisage an accounting course or module being constructed around such a selection of literature, perhaps reinforced by consideration of the relevant historical and professional contexts. Such a course might be 'packaged' primarily as accounting history albeit significantly grounded in appropriate literature. Some degree elements along these lines, indeed, are one possible prescription to meet the central concerns of the author (with which we have much sympathy). The benefits of studying history are recognized widely and include both those which are perhaps of more immediate relevance to professional work (such as the ability to assess evidence) and those which have a more general humane element (such as enhancement of moral understanding). This approach might easier meet the concerns - of students, educators and professional stakeholders - as to irrelevance, lack of time and cost, which may greet calls for the general literature education suggested by the 
author. A study of accounting and finance in the speculative climate of Victorian Britain, utilizing such texts as Trollope's The Way We Live Now, for example, suggests obvious parallels with our contemporary financial state. At the same time this type of innovation in accounting education might go at least some way to addressing the author's concerns as to the lack of reflection, creativity and imagination in accounting education.

\section{References}

Buckmaster, D. and Buckmaster, E. (1999) Studies of accounting and commerce in Chaucer's Shipman's Tale, Accounting, Auditing and Accountability Journal, 12 (1), pp. 113-128.

Czarniawska, B. and Rhodes, C. (2006), Strong plots: popular culture in management practice \& theory, in: Czarniawska, B. and Gagliardi, P. (Eds) Management Education and Humanities, pp. 195-218 (Cheltenham: Edward Elgar).

Czarniawska-Joerges, B. and Guillet de Monthoux, P. (Eds.) (1994) Good Novels, Better Management. Reading Organizational Realities (Chur: Harwood Academic Publishers).

Evans, L. (forthcoming) A Witches' Dance of Numbers': Fictional Portrayals of Business and Accounting Transactions at a Time of Crisis, Accounting, Auditing and Accountability Journal.

Fraser, I.A.M., Gallhofer, S., Haslam, J. and Sydserff, R. (2006) Hard Times: Carlyle and Dickens on an accounting in the name of social progress, paper presented at the Interdisciplinary Perspectives On Accounting Conference, Cardiff.

Jackson, M.W. (1992) Goethe's economy of nature and the nature of his economy, Accounting, Organizations and Society, 17 (5), pp. 459-469. 
Maltby, L. (1997) Accounting and the soul of the middle class: Gustav Freytag's Soll und Haben, Accounting, Organizations and Society, 22 (1), pp. 69-87.

Parker, R.H. (1999) Accounting in Chaucer's Canterbury Tales, Accounting, Auditing and Accountability Journal, 12 (1), pp. 92-112.

Phillips, N. (1995) Telling Organizational Tales: On the Role of Narrative Fiction in the Study of Organizations, Organization Studies, 14 (4), pp. 625-649.

Riahi-Belkaoui, A. (1996) Accounting, A Multiparadigmatic Science (Westport, CT: Quorum Books).

Stone, D. N. (2001) Accountant's tales, Accounting, Organizations and Society, 26 (4-5), pp. 461-470.

West, B.P. (2001) On the social history of accounting: The Bank Audit by Bruce Marshall, Accounting History, 6 (1), pp.11-30. 